\title{
Diagnostic Methods of Ectopic Pregnancy and Early Pregnancy Loss: a Review of the Literature
}

\section{Diagnostische Methoden bei Frühabort und Extrauteringravidität: eine Übersichtsarbeit}

Authors

Affiliations
A. Hamza ${ }^{1}$, G. Meyberg-Solomayer ${ }^{1}$, I. Juhasz-Böss ${ }^{1}$, R. Joukhadar ${ }^{1}$, Z. Takacs $^{1}$, E.-F. Solomayer ${ }^{1}$, S. Baum ${ }^{1}$, J. Radosa ${ }^{1}$, L. Mavrova ${ }^{1}$, D. Herr $^{2}$

${ }^{1}$ Department of Obstetrics and Gynaecology, Homburg University Medical Centre, Homburg

${ }^{2}$ Department of Obstetrics and Gynaecology, Würzburg University Medical Centre, Würzburg
Key words

- early pregnancy loss

- fetal demise

- $\beta$-hCG

Schlüsselwörter

- Frühabort

- Fruchttod

- Extrauteringravidität

- $\beta$-hCG

- Ultraschall
- ectopic pregnancy

ultrasound

\section{Abstract}

$\nabla$

This review article presents recent evidence on early pregnancy loss and ectopic pregnancy. In the light of recent evidence, the $\beta$-hCG discriminatory zone may be extended in clinically stable cases without evidence of bleeding. A possible cut-off is $4300 \mathrm{mIU} / \mathrm{ml}$, which corresponds to when a sonographer should detect an intrauterine pregnancy. Embryonic demise can be confirmed when a transvaginal ultrasound finding shows no heartbeat in an embryo of more than $7 \mathrm{~mm}$ CRL, no embryo in a gestational sac having a mean sac diameter of more than $25 \mathrm{~mm}$, or no appearance of an embryo within 7-10 days after the primary examination. These are considered definitive signs of embryonic demise. Suggestive signs of embryonic demise require closer monitoring of the pregnancy.

\section{Zusammenfassung \\ $\nabla$}

Der vorliegende Übersichtsartikel gibt einen Überblick über die neuesten Forschungsergebnisse zu Frühabort und Extrauteringravidität. Nach den neuesten Forschungsergebnissen könnte der Referenzbereich für $\beta$-hCG-Werte in klinisch stabilen Patientinnen ohne Blutungen ausgedehnt werden. Als möglicher Cut-off-Wert wird ein Wert von $4300 \mathrm{mIU} / \mathrm{ml}$ diskutiert, welcher ungefähr dem Zeitpunkt entspricht, an dem die Schwangerschaft auch per Ultraschall festzustellen sein sollte. Ultraschall kann zur Bestätigung eines Frühaborts dienen, wenn sich bei einem Embryo mit einer SSL von mehr als $7 \mathrm{~mm}$ keine Herztätigkeit feststellen lässt, bzw. sich kein Embryo in einer Fruchtblase mit einem durchschnittlichen Durchmesser von mehr als $25 \mathrm{~mm}$ befindet, oder wenn kein Embryo innerhalb von 7-10 Tagen nach der Erstuntersuchung aufzufinden ist. Diese Befunde sind allesamt als definitive Hinweise auf einen embryonalen Tod zu werten. Bei Anzeichen, die auf einen Frühabort hindeuten, ist eine engmaschige Überwachung der Patientin notwendig.

\section{Introduction}

\section{Abbreviations}

B-hCG

$\beta$ subunit of human chorionic gonadotrophin

23. 11.2015

accepted 24.11.2015

\section{Bibliography}

Dol http://dx.doi.org/

10.1055/s-0041-110204

Geburtsh Frauenheilk 2016; 76:

377-382 @ Georg Thieme

Verlag KG Stuttgart · New York . ISSN 0016-5751

\section{Correspondence}

\section{Amr Hamza}

Department of Obstetrics

and Gynecology

University of Saarland

66421 Homburg

amr.hamza@uks.eu $\begin{array}{ll}\text { CRL } & \text { Crown rump length } \\ \text { CDC } & \text { Centers for Disease Control }\end{array}$ and Prevention

i.m. Intramuscular

i.v. Intravenous

MSD Mean sac diameter
The primary target of an effective and efficient prenatal care system is to differentiate low from high risk pregnancies. A low risk pregnancy reflects a physiological course of gestational events, which requires distant monitoring for any abnormalities that would detect an abnormality that allows for reclassification of the gestation. Conversely, a high risk pregnancy requires a closer follow-up performed in specialized prenatal care facilities, thus reducing the probability of perinatal morbidity and mortality [1-3].

Two of the primary targets of prenatal surveillance is diagnosing abnormalities such as ectopic pregnancies, and detecting early pregnancy loss. 


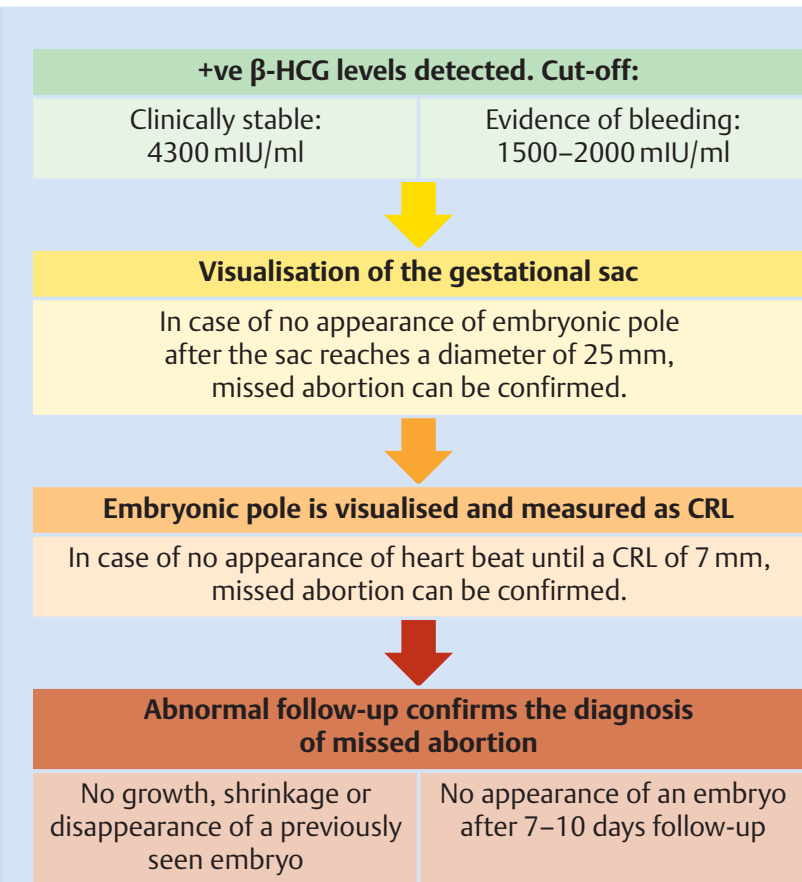

Fig. 1 The diagnosis of early pregnancy summarized in a flow chart. abortions occur before the 12th week of gestation, whereas after the 15th week, the overall risk for spontaneous abortion is approximately $0.6 \%[10]$. According to an embryoscopic and cytogenetic analysis of 233 missed abortions during the first trimester, $75 \%$ of the cases had an abnormal karyotype, $18 \%$ had a normal karyotype with a morphological defect, and $7 \%$ of cases had no embryonic or chromosomal abnormality. In this study, missed abortions were examined using a hysteroscope for morphological analyses, and an additional fetal or embryonic karyotype was done to complete the diagnosis [11]. More recent research shows that the current cut-offs of the mean gestational sac at which no embryo is seen, and crown-to-rump (CRL) lengths at which no heartbeat is seen, lead to the misdiagnosis of healthy pregnancies [12].

In some instances, the diagnosis is a visual diagnosis, e.g. in cases when the embryo showed a positive heartbeat that later ceased to persist, while in other cases the situation can be much more difficult, for example where the mean sac diameter is $23 \mathrm{~mm}$ without an evident embryo. In such an unclear clinical scenario, the obstetrician or sonographer is left with a dilemma of informing the patient about a poor, good, or undefined gestational prognosis. Thus, the diagnostic spectrum ranges between extremes. To avoid diagnostic errors with fatal consequences, extensive knowledge about the embryonic development in early pregnancy is crucial. Therefore, this review summarizes the available data relating to the impact of amenorrhea, $\beta$-hCG-levels, and sonographic signs for the diagnosis of early pregnancy.

\section{Significance of Amenorrhea}

$\nabla$

Amenorrhea is the absence or abnormal cessation of the menses. It is sub-classified into primary and secondary amenorrhea according to the time of occurrence. Primary amenorrhea is defined as the absence of menses by the age of 15 in the presence of secondary sexual characters and normal growth. This is also known as the absence of menarche [13]. Secondary amenorrhea is defined as the absence of menses for more than three cycles or six months in women who previously had menses. The most common cause of secondary amenorrhea is pregnancy, making it a cardinal sign of pregnancy. Lactation, pregnancy, and menopause cause secondary amenorrhea in $96-97 \%$ of cases. The remaining $3-4 \%$ are due to pathological causes $[14,15]$. It is therefore important to rule out pregnancy in cases of secondary amenorrhea, even if a patient reports having sexual intercourse during a safe period, under hormonal or barrier contraception. Confirming or ruling out a pregnancy is most reliably done by determining or detecting $\beta$-hCG in maternal serum or urine.

\section{Positive $\beta$-hCG in the Urine and/or Serum \\ $\nabla$}

$\beta$-hCG is secreted by the conceptus in the maternal circulation after implantation. After fertilization, between the 8th and 10th day post ovulation, the conceptus migrates towards the uterine cavity, usually implanting itself by an aggressive burrowing under the endometrium, and $\beta$-hCG is secreted into the maternal circulation. Subsequently, the $\beta$-subunit of $\beta$-hCG is detectable in the maternal serum and in the urine using immunoassay techniques $[16,17]$. There are different commercially available assays, having different standards. Therefore, it is important, if a followup is done, to use the same immunoassay. 
$\beta$-hCG can be detected as early as six days after presumed conception and peaks between 56 and 68 days, with a nadir at 18 weeks. In a normal, intrauterine pregnancy, during the first 30 days after implantation, the $\beta$-hCG measured doubles every 29 to 53 hours. An ectopic or unhealthy pregnancy shows a slower rise or even decline of the level in maternal serum [18-20] and no secondary rise of $\beta$-hCG levels can be seen [21]. Based on this, measurement of the $\beta$-hCG can indirectly give a hint of the vitality of the pregnancy.

$\beta$-hCG can be detected in the serum long before the pregnancy is visible using ultrasound techniques. Many studies were conducted to determine the minimum and maximum levels by which an embryo has to be seen. The serum level of $\beta$-hCG above which a gestational sac should be visualized is called the discriminatory zone for $\beta$-hCG [22], which is considered to be between 1500 to $2000 \mathrm{mIU} / \mathrm{ml}$ [23]. This level is obviously higher (6500 IU/L) using transabdominal ultrasound. In earlier publications thresholds of 1000, 1500, and $2000 \mathrm{mIU} / \mathrm{ml}$ were published, which might seem contradictory $[23,24]$.

Due to some confounding variables, $\beta$-hCG levels may be elevated above expected, thus crossing the $2000 \mathrm{mIU} / \mathrm{ml}$ level without any sonographic evidence of gestation.

While measuring $\beta$-hCG alone can be an indirect test to assess the vitality of the pregnancy, a combination with sonographic examination can improve the accuracy of this method. The variations in resolution, transducer frequencies, manufacturers of ultrasound scanners and sonographers play a significant role in the detection of small gestational sacs $[8,27]$.

The German guidelines, AWMF, state that a chorionic sac should be detected starting from a $\beta$-hCG level of $1500 \mathrm{mIU} / \mathrm{ml}$. A cut-off after which the absence of an intrauterine pregnancy should be suspected is not given [55].

There are conflicting opinions about the upper limit of the discriminatory zone using $\beta$-hCG when combining it with transvaginal ultrasound. Recent trials tend to lift the upper limit of the discriminatory zone in order to avoid erroneously destroying healthy pregnancies [27]. Mehta et al. analyzed 676 pregnancies and showed that taking a cut-off of $2000 \mathrm{mIU} / \mathrm{ml}$ would miss one third of the intrauterine pregnancies [8]. In another study, Doubilet et al. examined 202 cases, where transvaginal ultrasonography showed no intrauterine evidence of pregnancy with a positive $\beta$-hCG test on the same day; $4.5 \%$ of the cases showed a $\beta$-hCG of above $2000 \mathrm{mIU} / \mathrm{mL}$. In this series, none of the cases were diagnosed with extrauterine gestation. The highest value that preceded a live-born term baby was $4336 \mathrm{mIU} / \mathrm{mL}$. In this cohort, $13.8 \%$ of cases had an "uncertain" first trimester outcome, $77.2 \%$ were vital pregnancies by the end of the first trimester, and $9 \%$ had spontaneous first-trimester pregnancy loss; $66.8 \%$ of all the gestations were live born. The authors concluded that in cases when sonographic findings are inconclusive, the $\beta$-hCG discriminatory level should not be used to determine the management of a hemodynamically stable patient with suspected ectopic pregnancy [27].

\section{Sonographic Evaluation of an Intrauterine Early Pregnancy}

$\nabla$

Prerequisites for establishing a proper diagnosis

A technically adequate exam, using high resolution transvaginal ultrasound devices performed by an experienced sonographer, is the basic requirement for a proper diagnosis.
As the uterus is inside the bony pelvis, the best visualization is achieved by transvaginal sonography. As the pregnancy continues and the uterus rises outside the pelvis, transabdominal sonography becomes the method of choice [28].

\section{Physiological sonographic findings}

in early embryonic development

Basically, the sonographic structures appear in sequence. The first sonographic sign is the gestational sac, which is usually visible at 4.5 to 5 weeks of gestation. It is characterized by an echolucent sac surrounded by two concentric echogenic rims, also called double sac sign, appearing at 5.5 to 6 weeks [29]. This sac is usually round in shape and the echogenic rim represents the chorionic cavity. The intradecidual sign describes a fluid collection inside an echogenic rim located within a markedly thickened decidua on the lateral aspect of the uterine cavity [30]. Once this gestational sac is detected in an intrauterine location, an intrauterine pregnancy is diagnosed. Except for rare cases of heterotopic pregnancies, a normal course of events is expected [31]. Since the sac grows by approximately $1 \mathrm{~mm} / \mathrm{d}$, measuring the sac can be used to date the pregnancy. Therefore, calipers should be placed inside the sac, not including the echogenic rim. Most modern ultrasound devices can calculate the gestational age based on the sac diameter. Measuring the mean sac diameter (MSD) is done by calculating the mean of three orthogonal sac diameter measurements. However, with progressive pregnancy, this procedure is less accurate.

The next structure that appears during the embryonic development is the yolk sac. It can be detected at the start of the 5th gestational week confirming an intrauterine healthy pregnancy. Morphologically, it is described as a round structure with echolucent center and echogenic periphery [32]. The yolk sac reaches a maximal diameter of $6 \mathrm{~mm}$ at the age of 10 weeks [33], then it migrates to the periphery of the sac and disappears [34]. Thereafter, the embryo appears, which has also been designated as the embryonic pole or embryonic disc [35].

With ongoing pregnancy, the CRL can be measured. It is the standard biometric measurement of the embryo in the first trimester, defined as the longest straight line from the cephalic to caudal (rump) end of the embryo [36]. It can determine the gestational age with an accuracy of plus/minus three days [37,38]. Within this embryo, the embryonic heartbeat appears between 5.5 and 6 weeks of gestation, after which the risk of an abortion is reduced. However, after the 15th week of pregnancy, the accuracy of the CRL is reduced to within \pm 8.4 days [40]. Between the $11+0$ and $13+6$ weeks of pregnancy, the nuchal translucency can be measured and correlated with patient and biochemical data to calculate the risk for trisomy 13,18 and 21 [39].

\section{Pathological sonographic findings}

in early embryonic development

Despite technical advances and sonographer training, human errors and physiological variations can result in over- and underestimation of the gestational age, which may lead to misdiagnosis. Different equations are used to curtail errors, yet cannot eliminate them $[41,42]$. Extensive research has been conducted to reduce errors and avoid the misdiagnosing an early pregnancy loss. Therefore, signs of fetal demise have been subdivided into definitive and suggestive signs.

Definitive signs are indicators of a missed abortion, and the presence of one of the signs is enough for such a diagnosis. Each definitive sign and its reasoning is described below [12] ( $\bullet$ Fig. 1): 

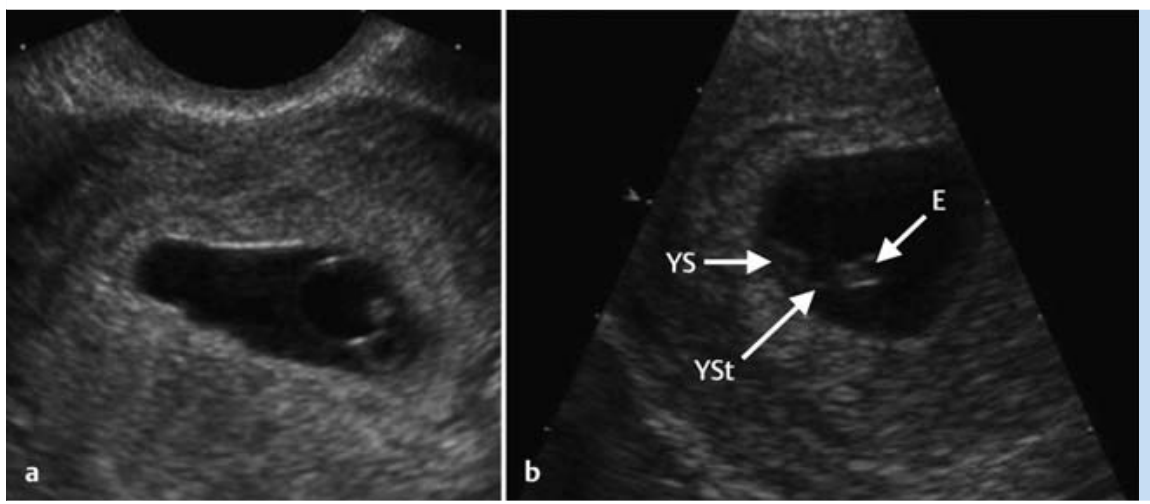

Fig. $2 \mathbf{a}$ and $\mathbf{b}$ a Expanded amnion sign: transvaginal US of a small embryo surrounded by an amniotic sac. This sac is too big for the measured CRL. For early embryos, the CRL is proportionally related to the amnion diameter. This embryo should be approximately $10 \mathrm{~mm}$ in size, much larger than in this case (published with permission) [46]. b Yolk stalk: an embryo (E) of a CRL $<5 \mathrm{~mm}$ and no cardiac activity. Although short, a yolk stalk (YSt) can be recognized separating the embryo from the yolk sac (YS), which indicates a more advanced gestational age than would have been concluded from the CRL alone (published with permission) [49].

- No embryo in the gestational sac with mean sac diameter of more than $25 \mathrm{~mm}$.

The previous cut-off for the gestational sac diameter used for case of an empty sac, using transvaginal ultrasound, was 16 and $20 \mathrm{~mm}$. Setting the cut-off at $16 \mathrm{~mm}$ will have a $4.4 \%$ false positive rate, i.e. $4.4 \%$ will be pregnancies falsely terminated, while setting a cut-off at $20 \mathrm{~mm}$ will give a $0.5 \%$ false positive rate [12]. One study found an $18.78 \%$ interobserver variation when measuring a mean sac diameter of $20 \mathrm{~mm}$ with an interobserver variation span from 16.8 to $24.5 \mathrm{~mm}$. Taking this observation into account, the cut-off of the gestational sac diameter could be extended to $25 \mathrm{~mm}$ to reduce the false positive rate to $0.5 \%$ [12].

- No heart beat in an embryo of more than $7 \mathrm{~mm}$ CRL.

In current practice, a pregnancy is labeled as a missed abortion if an embryo reaches a CRL of 5-6 mm with no evidence of heartbeat. The German guidelines mention that a heartbeat should be seen starting from a mean sac diameter of $20 \mathrm{~mm}$ (55). When measuring a CRL of $5 \mathrm{~mm}$, there was an inter-observer variation from 4.1 to $5.9 \mathrm{~mm}$. A CRL of $6 \mathrm{~mm}$ had an inter-observer variation of 5.4 to $6.7 \mathrm{~mm}$. It is therefore recommended to extend the CRL at which a heartbeat should be seen to $7 \mathrm{~mm}$.

- No growth, shrinkage or disappearance of a previously seen embryo.

- No appearance of an embryo after 7-10 days follow-up.

In contrast to the definitive signs, the suggestive signs of fetal demise have not proven to be as powerful in the prediction of embryonic demise as definitive signs in larger studies. Thus, these signs are taken as warning signs of possible miscarriage and indicate the need for serial sonographic monitoring. The more suggestive signs found in a pregnancy, the worse the prognosis. Below is an explanation of the suggestive signs:

\section{Embryonic bradycardia}

As mentioned before, the embryonic heartbeat should be seen using transvaginal ultrasound by 6 weeks post-menstrualis. Thereby, the embryonic heart rate increases between 5.5 to 10 weeks from 100 to $150-140$ beats per minute. Embryonic bradycardia between 6 to 8 weeks of gestation, defined as less than 110 beats per minute, is suggestive of a poor prognosis. Again, a sonographic follow up is recommended within three to four weeks [43].

First trimester oligohydramnios, small gestational sac Sonomorphologically, a small sac is relative to the size of the embryo being observed. The quantitative method to estimate a small gestational sac is by subtracting the CRL in $\mathrm{mm}$ from the mean sac diameter in $\mathrm{mm}$. If it is less than $5 \mathrm{~mm}$, subsequent demise can be predicted in $94 \%$ of cases [44]. Although often having a poor outcome, studies have shown a $35 \%$ survival rate, making it only a suggestive sign and not a definitive sign for termination [45].

\section{The expanded amnion sign}

This sign can be detected sonographically since a relation is observed between the amniotic sac and the embryo. Normally the amnion grows in direct linear proportion to the CRL. Seeing the amniotic cavity indirectly implies the presence of an embryo with a positive heartbeat. An absence of a heartbeat suggests embryonic demise, yet the sign by which the termination of pregnancy is recommended must be the absence of a heartbeat in an embryo with a CRL of more than $7 \mathrm{~mm}$. Other amniotic abnormalities with poor embryonic outcomes are amniotic cavities with a wavy outline and a thick amnion that approaches the yolk sac thickness $[46,47]$ (๑ Fig. 2).

\section{Embryonic growth rate}

A growth rate of less than $0.673 \mathrm{~mm}$ a day used to be a cut-off for suspecting a miscarriage. This observation was reported to have a specificity of $90.1 \%$ and a sensitivity of $61.7 \%$ for diagnosing miscarriage. Reports suggest using a cut-off $\leq 0.2 \mathrm{~mm}$ per day to predict a miscarriage to minimize the false positive diagnosis to zero [48]. In contrast, clinical practice takes into account that a slow or even absent growth rate of the gestational sac is not necessarily associated with miscarriage. The new cut-off value for CRL growth of $0.2 \mathrm{~mm}$ a day is always linked with embryonic demise. Yet, it is not recommended to use the growth rate abnormalities of the gestational sac alone as a marker of fetal demise [48].

\section{Yolk sac abnormalities}

Yolk sac abnormalities affect the size (size more than $6 \mathrm{~mm}$ ), the number (more than one per embryo), the shape (irregular) or the echogenicity (solid or calcified). In the literature, a yolk stalk sign was described. This sign occurs when an embryo, smaller than $5 \mathrm{~mm}$, is identified without a visible heartbeat yet the embryo is not immediately adjacent to the yolk sac. In healthy pregnancies, the yolk stalk does not exist in the early phases. In contrast, the mentioned sign was observed in pregnancies that ended in fetal demise [49].

\section{Presence of blood in the uterine cavity}

Blood seen sonographically as echogenic debris or a fluid level in the uterine cavity is also a negative predictor. A chorionic bump is an uncommon finding during pregnancy that may be a hematoma bulging into the gestational sac or a resorbing twin. This 


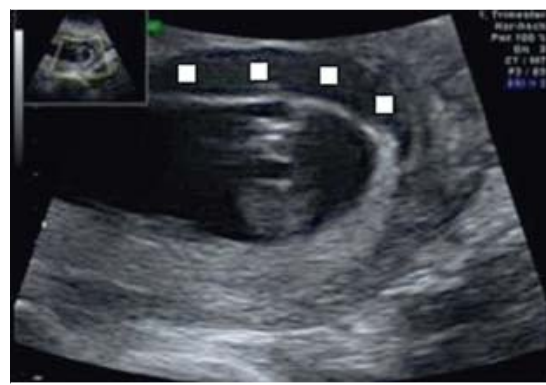

Fig. 3 Retrochorial hematoma in the first trimester on lining the anterior wall of the uterus (marked by multiple white squares in the image - image provided by the authors).

should draw the attention of obstetricians to closely follow up the pregnancy [50]. It was also reported that subchorionic bleeding may correlate with embryonic demise. However, this is not clear cut [51] (๑ Fig. 3).

Low implantation site of the embryo or gestational sac A low implantation position may indicate an abortion in progress. This is detected sonographically by caudal movement of the sac and clinically by vaginal bleeding and dilatation of the cervix. In addition, it may also indicate cervical ectopic pregnancy, which is associated with a negative maternal and embryonic outcome, a nabothian cyst, or a normal sac with a uterine contraction [52].

\section{Heterotopic pregnancy}

Finally, a pregnancy being intact and intrauterine does not exclude a concurrent extrauterine pregnancy. This is termed as an heterotopic pregnancy. The incidence of heterotopic pregnancy ranges between $1 / 3889$ to $1 / 30000$ in the general population, yet shows an incidence of $1 / 100$ in pregnancies following in vitro fertilization with embryo transfer $[53,54]$. Due to the presence of intrauterine gestation, the diagnosis of a heterotopic pregnancy remains challenging. The extrauterine pregnancy may be located in the fallopian tube, cervix, caesarean section scar. The latter one is expected to increase alongside with the increasing rate of caesarean sections [56,57].

\section{Conclusion}

Based on the retrospective studies reviewed, the diagnosis of early pregnancy loss and ectopic pregnancy could be made more accurate with a reduction in unnecessary terminations of physiological gestations. The new extensions of $\beta$-HCG, definitive and suggestive signs could therefore reassure the physician in offering a more confident diagnosis for the patient.

\section{Funding Statement}

This manuscript was funded and supported by the Department of Obstetrics and Gynecology of the University of Saarland.

\section{Acknowledgements}

I thank the coauthors, reviewers, editors and editorial board for their support and fruitful contribution to our manuscript.

\section{Conflict of Interest}

\section{$\nabla$}

None.

\section{References}

1 Murray H, Baakdah H, Bardell T et al. Diagnosis and treatment of ectopic pregnancy. CMAJ 2005; 173: 905-912

2 Layman K, Antonis M, Davis JE. Pitfalls in emergency department focused bedside sonography of first trimester pregnancy. Emerg Med Int 2013; 2013: 982318

3 van Mello NM, Mol F, Ankum WM et al. Ectopic pregnancy: how the diagnostic and therapeutic management has changed. Fertil Steril 2012; 98: 1066-1073

4 Centers for Disease Control and Prevention (CDC). Ectopic pregnancyUnited States, 1990-1992. MMWR Morb Mortal Wkly Rep 1995; 44 : 46-48

5 Kamwendo F, Forslin L, Bodin L et al. Epidemiology of ectopic pregnancy during a 28 year period and the role of pelvic inflammatory disease. Sex Transm Infect 2000; 76: 28-32

6 Alsuleiman SA, Grimes EM. Ectopic pregnancy: a review of 147 cases. J Reprod Med 1982; 27: 101-106

7 Kadar N, DeVore G, Romero R. Discriminatory hCG zone: its use in the sonographic evaluation for ectopic pregnancy. Obstet Gynecol 1981; 58: $156-161$

8 Mehta TS, Levine D, Beckwith B. Treatment of ectopic pregnancy: is a human chorionic gonadotropin level of $2,000 \mathrm{mIU} / \mathrm{mL}$ a reasonable threshold? Radiology 1997; 205: 569-573

9 Regan L, Rai R. Epidemiology and the medical causes of miscarriage. Baillieres Best Pract Res Clin Obstet Gynaecol 2000; 14: 839-854

10 Wyatt PR, Owolabi T, Meier C et al. Age-specific risk of fetal loss observed in a second trimester serum screening population. Am J Obstet Gynecol 2005; 192: 240-246

11 Philipp T, Philipp K, Reiner A et al. Embryoscopic and cytogenetic analysis of 233 missed abortions: factors involved in the pathogenesis of developmental defects of early failed pregnancies. Hum Reprod 2003; 18 : 1724-1732

12 Abdallah Y, Daemen A, Kirk E et al. Limitations of current definitions of miscarriage using mean gestational sac diameter and crown-rump length measurements: a multicenter observational study. Ultrasound Obstet Gynecol 2011; 38: 497-502

13 Practice Committee of the American Society for Reproductive Medicine. Current evaluation of amenorrhea. Fertil Steril 2006; 86 (5 Suppl. 1): S148-S155

14 Pettersson F, Fries H, Nillius SJ. Epidemiology of secondary amenorrhea. I. Incidence and prevalence rates. Am J Obstet Gynecol 1973; 117: 8086

15 Fries H, Nillius SJ, Pettersson F. Epidemiology of secondary amenorrhea. II. A retrospective evaluation of etiology with special regard to psychogenic factors and weight loss. Am J Obstet Gynecol 1974; 118: 473-479

16 Cole LA, Ladner DG, Byrn FW. The normal variabilities of the menstrual cycle. Fertil Steril 2009; 91: 522-527

17 Wilcox AJ, Baird DD, Weinberg CR. Time of implantation of the conceptus and loss of pregnancy. N Engl J Med 1999; 340: 1796-1799

18 Daya S. Human chorionic gonadotropin increase in normal early pregnancy. Am J Obstet Gynecol 1987; 156: 286-290

19 Kadar N, DeCherney AH, Romero R. Receiver operating characteristic (ROC) curve analysis of the relative efficacy of single and serial chorionic gonadotropin determinations in the early diagnosis of ectopic pregnancy. Fertil Steril 1982; 37: 542-547

20 Barnhart KT, Sammel MD, Rinaudo PF et al. Symptomatic patients with an early viable intrauterine pregnancy: HCG curves redefined. Obstet Gynecol 2004; 104: 50-55

21 Braunstein GD, Rasor J, Danzer $H$ et al. Serum human chorionic gonadotropin levels throughout normal pregnancy. Am J Obstet Gynecol 1976; 126: 678-681

22 Braffman BH, Coleman BG, Ramchandani P et al. Emergency department screening for ectopic pregnancy: a prospective US study. Radiology 1994; 190: 797-802

23 Barnhart K, Mennuti MT, Benjamin I et al. Prompt diagnosis of ectopic pregnancy in an emergency department setting. Obstet Gynecol 1994; 84: $1010-1015$ 
24 Condous G, Kirk E, Lu C et al. Diagnostic accuracy of varying discriminatory zones for the prediction of ectopic pregnancy in women with a pregnancy of unknown location. Ultrasound Obstet Gynecol 2005; 26: 770-775

25 Linskens IH, Engels $M$, Oepkes $D$ et al. A trend toward increased first trimester free beta-hCG and PAPP-A in monochorionic twins complicated by Twin-to-Twin Transfusion syndrome. Prenat Diagn 2010; 30: 909910

26 Chasen ST, Perni SC, Predanic $M$ et al. Does a "vanishing twin" affect first-trimester biochemistry in Down syndrome risk assessment? Am J Obstet Gynecol 2006; 195: 236-239

27 Doubilet PM, Benson CB. Further evidence against the reliability of the human chorionic gonadotropin discriminatory level. J Ultrasound Med 2011; 30: 1637-1642

28 Grisolia G, Milano K, Pilu G et al. Biometry of early pregnancy with transvaginal sonography. Ultrasound Obstet Gynecol 1993; 3: 403411

29 Bradley WG, Fiske CE, Filly RA. The double sac sign of early intrauterine pregnancy: use in exclusion of ectopic pregnancy. Radiology 1982; 143: $223-226$

30 Yeh HC, Goodman JD, Carr L et al. Intradecidual sign: a US criterion of early intrauterine pregnancy. Radiology 1986; 161: 463-467

31 Doubilet PM, Benson CB. Double sac sign and intradecidual sign in early pregnancy: interobserver reliability and frequency of occurrence. J Ultrasound Med 2013; 32: 1207-1214

32 Levi CS, Lyons EA, Lindsay DJ. Early diagnosis of nonviable pregnancy with endovaginal US. Radiology 1988; 167: 383-385

33 Lindsay DJ, Lovett IS, Lyons EA et al. Yolk sac diameter and shape at endovaginal US: predictors of pregnancy outcome in the first trimester. Radiology 1992; 183: 115-118

34 Jauniaux E, Jurkovic D, Henriet $Y$ et al. Development of the secondary human yolk sac: correlation of sonographic and anatomical features. Hum Reprod 1991; 6: 1160-1166

35 Nyberg DA, Mack LA, Laing FC et al. Distinguishing normal from abnormal gestational sac growth in early pregnancy. J Ultrasound Med 1987; 6: $23-27$

36 Deter RL, Buster JE, Casson PR et al. Individual growth patterns in the first trimester: evidence for difference in embryonic and fetal growth rates. Ultrasound Obstet Gynecol 1999; 13: 90-98

37 Robinson HP, Fleming JE. A critical evaluation of sonar "crown-rump length" measurements. Br J Obstet Gynaecol 1975; 82: 702-710

38 Drumm JE, Clinch J, MacKenzie G. The ultrasonic measurement of fetal crown-rump length as a method of assessing gestational age. $\mathrm{Br}$ J Obstet Gynaecol 1976; 83: 417-421

39 Nicolaides $K H$, Wright $D$, Poon $L C$ et al. First-trimester contingent screening for trisomy 21 by biomarkers and maternal blood cell-free DNA testing. Ultrasound Obstet Gynecol 2013; 42: 41-50

40 Hadlock FP, Shah YP, Kanon DJ et al. Fetal crown-rump length: reevaluation of relation to menstrual age (5-18 weeks) with high-resolution real-time US. Radiology 1992; 182: 501-505
41 Hadlock FP, Deter RL, Harrist RB et al. Estimating fetal age: computerassisted analysis of multiple fetal growth parameters. Radiology 1984; 152: 497-501

42 Hadlock FP, Harrist RB, Shah YP et al. Estimating fetal age using multiple parameters: a prospective evaluation in a racially mixed population. Am J Obstet Gynecol 1987; 156: 955-957

43 Rauch ER, Schattman GL, Christos PJ et al. Embryonic heart rate as a predictor of first-trimester pregnancy loss in infertility patients after in vitro fertilization. Fertil Steril 2009; 91: 2451-2454

44 Bromley B, Harlow BL, Laboda LA et al. Small sac size in the first trimester: a predictor of poor fetal outcome. Radiology 1991; 178: 375-377

45 Rowling SE, Coleman BG, Langer JE et al. First-trimester US parameters of failed pregnancy. Radiology 1997; 203: 211-217

46 Yegul NT, Filly RA. The expanded amnion sign: evidence of early embryonic death. J Ultrasound Med 2009; 28: 1331-1335

47 Horrow MM. Enlarged amniotic cavity: a new sonographic sign of early embryonic death. AJR Am J Roentgenol 1992; 158: 359-362

48 Abdallah Y, Daemen A, Guha $S$ et al. Gestational sac and embryonic growth are not useful as criteria to define miscarriage: a multicenter observational study. Ultrasound Obstet Gynecol 2011; 38: 503-509

49 Filly MR, Callen PW, Yegul NT et al. The yolk stalk sign: evidence of death in small embryos without heartbeats. J Ultrasound Med 2010; 29: 237-241

50 Sana Y, Appiah A, Davison A et al. Clinical significance of first-trimester chorionic bumps: a matched case-control study. Ultrasound Obstet Gynecol 2013; 42: 585-589

51 Tuuli MG, Norman SM, Odibo AO et al. Perinatal outcomes in women with subchorionic hematoma: a systematic review and meta-analysis. Obstet Gynecol 2011; 117: 1205-1212

52 Alkatout I, Honemeyer $U$, Strauss A et al. Clinical diagnosis and treatment of ectopic pregnancy. Obstet Gynecol Surv 2013; 68: 571-581

$53 \mathrm{Li}$ XH, Ouyang Y, Lu GX. Value of transvaginal sonography in diagnosing heterotopic pregnancy after in-vitro fertilization with embryo transfer. Ultrasound Obstet Gynecol 2013; 41: 563-569

54 Oron G, Tulandi T. A pragmatic and evidence-based management of ectopic pregnancy. J Minim Invasive Gynecol 2013; 20: 446-454

55 Rempen A, Chaoui R, Kozlowski P et al. Standards zur Ultraschalluntersuchung in der Frühschwangerschaft AWMF 015/032 (S1). Reviewed and validated in 2004, 2006, 2008, 2010. Next validation planned in 2015. Frauenarzt 2001; 42: $327 \mathrm{ff}$.

56 Timor-Tritsch IE, Monteagudo A. Unforeseen consequences of the increasing rate of cesarean deliveries: early placenta accreta and cesarean scar pregnancy. A review. Am J Obstet Gynecol 2012; 207: 14-29

57 Armbrust R, Krätschell R, Henrich Wet al. Operative therapy for heterotopic scar pregnancy and successful birth of the intrauterine foetus case report and review of the literature. Geburtsh Frauenheilk 2015. 75: $384-388$ 